\title{
The Design and Implementation of College Volunteers Task Management Platform based on Dynamic Collaborative
}

\author{
Xiang Li, Lin Zhe Wang ${ }^{a}$ \\ College of Mathematics, Beihua University, Jilin City, China
}

\begin{abstract}
College volunteer's activities are currently linkages between societies and effective way. But the management of the university's volunteer is more difficulty. In order to effectively address these issues, it is necessary to construct volunteer's management platform system based on dynamic collaborative task according to the characteristics of volunteers and volunteer characteristics of scientific tasks assigned tasks, and task execution in the entire life cycle of the actual dynamic management, can effectively improve the work efficiency.
\end{abstract}

\section{General instruction}

Student volunteers are the main part of our youth volunteers, is an important carrier of ideological and moral education, but also to build a socialist core value system of the new carrier. In the social role theory perspective, in order to carry out clinical medical school "smoke-free hospitals, harmonious society," the volunteer activities, for example, investigate the source of motivation for college students volunteer service to study the "power source" mechanism, "intensity" mechanism, "force "mechanism system constitutes, in order to establish long-term mechanism Students volunteer work, volunteer college students to form a scientific and standardized service management model to promote the development of college students volunteer action in the socialist core value system in our country. The term was later introduced mechanisms of social science research, which originated from the Greek, originally referred to the construction and operation principle of the machine. After the introduction of social science research, its meaning is interrelated and each part of the social organism, the way of interaction. Dynamic mechanism is an important part of the mechanism, the mechanism of the system configuration and operation of the power of the group. This system consists of "power source" mechanism, "intensity" mechanism, "force fit" (together) constitute a mechanism.

Power source is to stimulate the development of the various needs of the people, and they need guidance, portrayed as reasonably necessary, the use of incentives, means the interests of science and culture means to achieve a fair and reasonable incentives. Social practice of student volunteers with full respect for the sense of participation of college students, advocates of the "dedication, friendship, mutual aid, and progress" volunteer spirit, reflecting the improvement in the relationship between people and mutual harmony between people and society and the harmonious coexistence between man and nature.

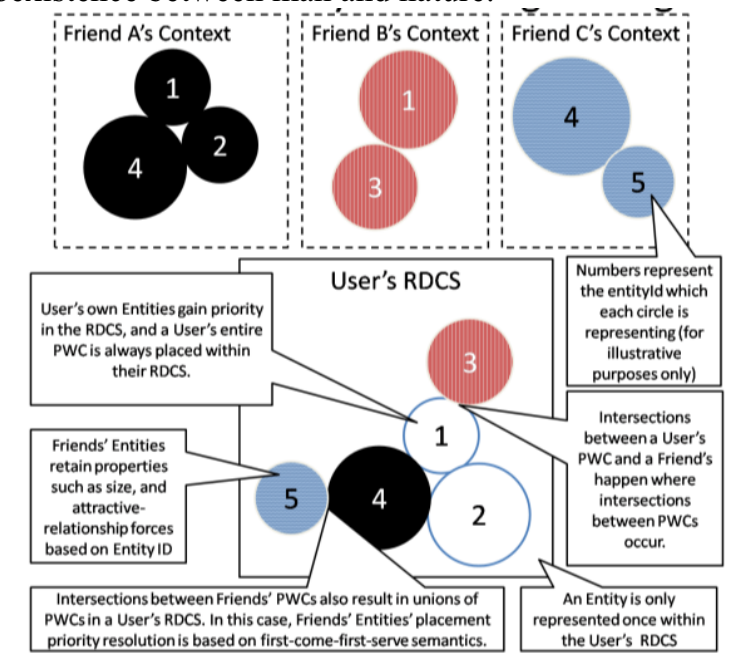

Figure 1. Collaborative dynamic neighbouring

\section{Incentive motivation "power source" mechanism}

Sense of participation, motivation is affecting young students volunteer to become an important factor, but also to maintain the ideological pillars of volunteers in the volunteer service organization in volunteer activities. Volunteers in volunteer service through honest labor to meet people's needs, so as to stimulate the enthusiasm of their volunteer service, make this an external driving force transformed into a self-powered hard work, full human potential.

As organizers of the Communist Youth League School of Mathematics and Student Management Office Ban first understand the motivation of volunteers participate

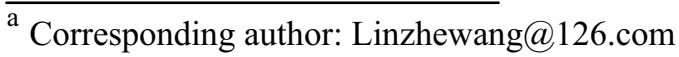


through questionnaires, interviews, training and other means. You can see from the interview, the main motivation for college students to participate in activities there are two aspects of social motivation benefits, such as they referred to "responsibility", "helping others", "to do something good for society," and so on; the second is personal motivation of development, such as they talk about the professional skills learned in theory can be applied to social practice, exercise their abilities, develop social interaction skills. Students understand the motivation for volunteers to participate in the service, we need to know what they are, and to take effective way to mobilize and train volunteer service activities. In the whole process of voluntary service, and for changing their psychological needs, take the corresponding excitation methods to enhance the degree of their psychological satisfaction, using the means assessment, appraisal, supervision, incentives, etc., to form a reasonable incentive to provide them social interaction between people and a platform for social interaction, forming a close interaction between people and care. Students' volunteer service through contact with objects, between people, between social groups set up mutual friendship and mutual help bridge understanding of the needs of the service object, a better understanding of the needs of society.

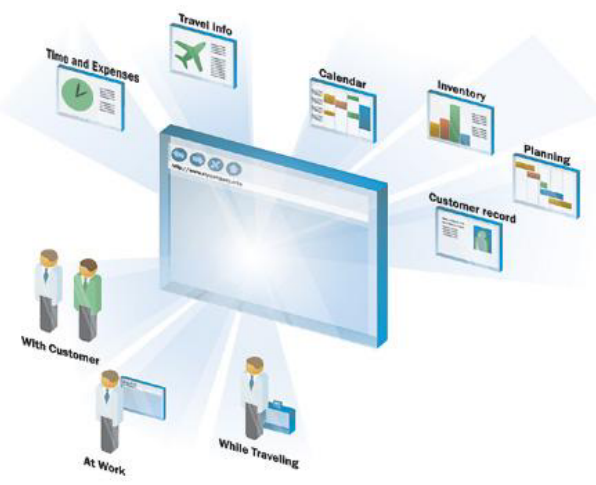

Figure 2.Communication between Volunteers with each system diagram

Harmonious society is the essence of all parts of society as a whole, the various elements of a balanced and orderly development. Thus equilibrium is a mechanism from the perspective of social governance, that is, the coordination of social equilibrium various interactions, co-ordination, adaptation, with its key interactions "degree" of the problem.

Therefore, a balanced and harmonious society efforts mechanism refers in particular to grasp hold of forces from all levels of social interaction with the start of the driving force behind the force, effectively resolve various contradictions problems. According to the structure of China's social development, college students volunteer service organization system, is relying on the Communist Youth League organized grassroots volunteer service organization system, take a variety of forms of student volunteers to strengthen universal knowledge and expertise in training, a rich personal life experience and life experience broaden the circle of life of individuals, society and life deep experience. Students involved in volunteer work in process, in addition to skills can play, the more you can develop self-organization and leadership skills, learn new knowledge and new skills, meet and feel a sense of accomplishment from work. The student volunteers activities on society: in the care to the community, but also passed the love, spread of civilization, this "love" and "civilization" from one person to another person who uploaded eventually converging to a powerful social warmth, help build a harmonious society, to promote social progress and have some positive effect.

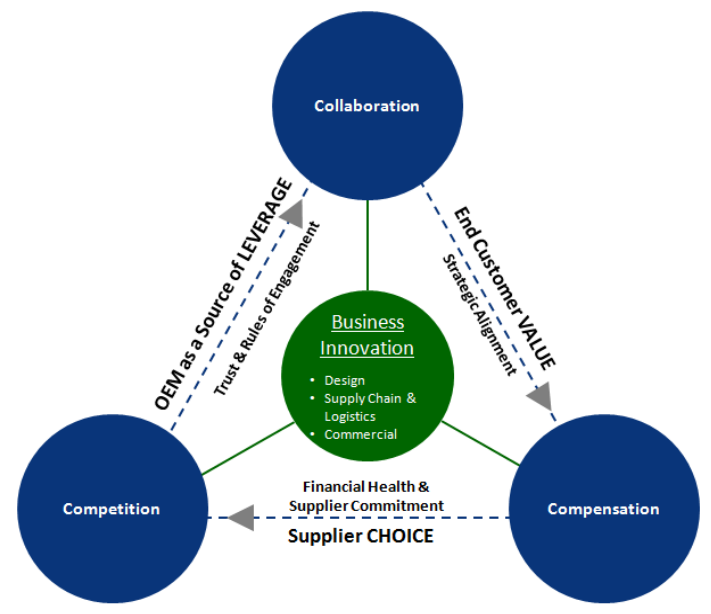

Figure 3.Competition and cooperation between volunteers

\section{The same mechanism to force}

Systems theory believes that the relationship between the whole and the parts of the system elements, and the elements interact together to form a system of external information and energy output. To meet the needs of most people's interests, the various combinations of positive force in the same direction, to gather and inspire them to build a harmonious society dynamic mechanism. The student volunteers practice; it is a process of construction of the system force mechanism. Meanwhile, according to the integrity of the system theory, dynamic, contact viewpoint, the integration of college students volunteer service organization resources, and concerted efforts of volunteer work. In practice, education and college students are to serve the community through practice, to understand the needs of society, and society interaction. To enjoy the social practice of advanced thinking and the pace of modernization, and to provide feedback on the social issues, these feedback and questions back to campus, back to the lab, targeted to improve their research methods and results, eliminate the absolute limits of the campus and the community. 


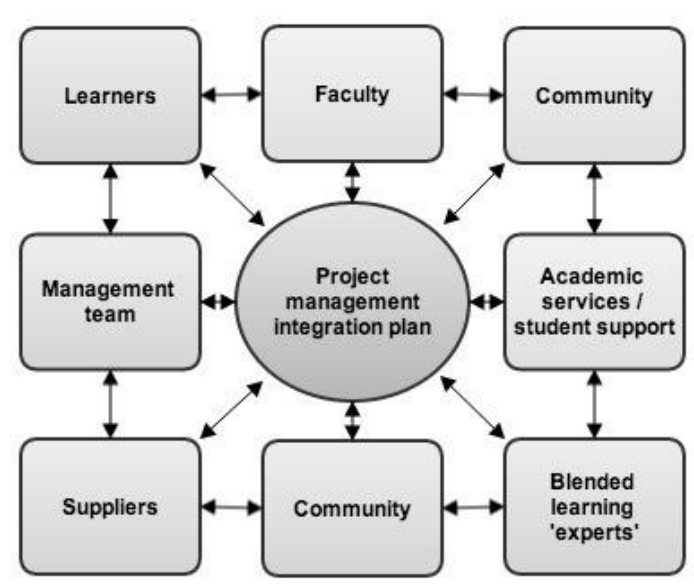

Figure 4.Project management integration plan

At present, the domestic academic research on volunteer service, and more focused on the general youth volunteer activities, while the student volunteers are a special group of young people, the less relevant research. This paper is based on the mathematical College student volunteers practice, for example, through the mechanism of power service to carry out the obligations of the student volunteers guide patient service activities, medical and social practice. Especially in the face of emergencies, emergency rescue volunteer service organizations, to enhance the campus emergency rescue service system construction, the establishment of a comprehensive emergency volunteer team to achieve a scientific, professional and community volunteer service mechanism. Standardized practice etiquette guide for diagnosis, specially invited professional etiquette teacher student volunteers related etiquette training and guidance to the student volunteers a better grasp of activity responsibilities. For example: In the process of smoking cessation advice, volunteers flexible, patient persuasion, to take a lot of humane measures, to each smoker made of sugar, to narrow the distance between each other, to facilitate the activities of. In practice, the spirited volunteers not only won the trust and support of patients and their families, has also been doctors, students' praise and affirmation.

\section{College students' socialist core values}

Research on college students' socialist core values recognized academics in a common theoretical studies, uncommon connotation and implementation research pathways. In fact, in order to be targeted to strengthen the college students socialist core values of education, exploration and research by ought to real natural state transition is necessary. The party's report is the socialist core values scouring the 24-word latest summarize marks party highly conscious in theory, but the spirit of volunteerism is included in the spiritual dimension of socialist core value system. Volunteering is as a new career study of its field relative later than in other Western countries. After twenty years of academic research and discussion, has now entered a rising phase. Peking University Political Development and
Government Management Institute Ding bamboo that "volunteerism is a voluntary, not for remuneration and income involved in human development, promote social progress and improve the spirit of community work, a public participation in social life is very important way, is the essence of civil society and civil society organizations. Since then, the domestic scholars continue to explore the theoretical system of voluntary service study proposed a new theory, producing a wealth of research results. Throughout the study in-depth development of voluntary service, volunteer service for their country and their organizations operating and regulating aspects of research, mostly around voluntary service connotation, theory, research and analysis, problems and countermeasures to cultivate volunteers and other aspects of operations. For voluntary service and research subject, content, organization development characteristics, reasons for volunteering flourishing lagging behind other aspects, the lack of these theories restricted the development of voluntary service. In addition, the volunteer organization is not mature enough. CPC Central Committee and the State in the new situation formally proposed strategic guidelines and requirements of the socialist core values, and to participate in volunteer activities is the best mode of practicing the socialist core values. The current theory is no specific depth study of how to play the spirit of volunteerism to promote and improve students on issues related to the socialist core values.

First, build the dynamic mechanism of volunteer service system for university students. Social practice of student volunteers, it contains a rich and deep ideological and moral education content, not only has the "service to others, self-education, and optimize the social environment," the function of the Trinity, also built up a scientific and standardized service management model to achieve a stable volunteer service team, has standardized management system, unique volunteer service brand, a fixed volunteer service system. The students volunteer service activities, an increase of double the capital of self and society, volunteering motivation, self-interest and altruism factors combined with each other. Students' volunteer altruistic volunteerism embodied in echoes that reflect voluntary personal love, not for remuneration to promote social development and promote social harmony and perfection; and reflected in the student volunteers selfish personal interests tend to exercise their social practice capacity. Therefore, for a long time college students volunteer service activities to develop, we must adhere to the needs of society at the same time, considering the inherent individual student volunteers reasonable demand, so that the two combine, win-win. Student volunteers in activities to instil knowledge of perception transformed into independent thinking, in order to achieve the ultimate goal of moral education, moral education to become self-sublimation quality and promote the effectiveness of ideological and moral education.

Next, the student volunteers more mature social psychology. In a correct understanding of the psychological development of the law of the premise, to 
strengthen the efforts of volunteers specifically for mental training. Organized centralized training and decentralized training combined; the universality of training and individual training combine; so that students vibrant volunteer work. Volunteer actions are enthusiastic social welfare services; they adhere to the democratic principles and respect for assistance objects, and have some expertise in their spare time, free to participate in community volunteer work. Their service activities actually fit individual needs and the reality provided opportunities for college students to experience the process of citizen volunteers to role change, but also an effective way of self-development, practice and training opportunities for volunteers to get involved in volunteer service activities more accelerated social and psychological maturity.

American sociologist David (Darvill) and Mundy (Mundy), they think volunteers "voluntarily to one or more non-relative, so who provide direct services pro bono," and "is not usually an informal neighbourhoods association, but rather to provide some kind of formal structure through his / her service. This definition is the crown for the most classic interpretation of volunteer's connotation. Richard - Pound (Richard Pound) believes that volunteers refers to the law and not subject to any other form of coercion, voluntary service person. Maria (Maria) to define the free and voluntary aspects that volunteers will contribute their spare time or knowledge to the service of others in useful activities. Without expecting anything in return the American people, "Red Cross" provides: "Red Cross volunteer is any one from beyond the usual salary and work responsibilities, to help achieve the mission of the Red Cross and donated their time and human service organizations to provide services not accepted by the people from the Red Cross paid. Penne: The spirit of volunteerism (volunteerism) is defined as: a long-term, planned, socially beneficial behaviour by the individual will decide, it makes the benefit of strangers, and occurs in the context of the organization. Potential changes in society, the voluntary sector in order to give the personal responsibility and location, provides both a people united coagulant, but also to promote social change dissolving agent. Voluntary sector is the use of government, but also to shape the government.

\section{References}

1. Qin Hui government and outside the modern enterprise - Western welfare comparative study. Hangzhou: Zhejiang People's Publishing House, 132(2009)

2. Ding Yuan Bamboo Chinese Volunteer Services Research [m] Beijing: Peking University Press, 15(2007)

3. Liu Shan, Feng Xiaotian Students Volunteer Service: motivation, and problem type. Shaanxi Youth Administrative Cadres College, 55(2005)
4. Tan Jianguang, Ling Chong, Zhu Liling modern city volunteer mentality analysis. China Youth Research, 101(2005)

5. Liu Min activities and student volunteers to build a harmonious campus.New West: half [m] Peking University Press,21(2007)

6. Ding Yuan Bamboo volunteerism function in building a socialist core value system. Beijing: Peking University Press, 67(2008) 